\title{
Curvature Contrast in Stereoscopically-Defined
} Surfaces

\section{S.F. te Pas, B.J. Rogers and T. Ledgeway}

\section{(2) OpenEdition}

\section{Journals}

\section{Electronic version}

URL: http://journals.openedition.org/cpl/110

DOI: $10.4000 / \mathrm{cpl} .110$

ISSN: $1379-6100$

\section{Publisher}

Centre PsyCLÉ

\section{Printed version}

Date of publication: 1 April 2000

\section{Electronic reference}

S.F. te Pas, B.J. Rogers and T. Ledgeway, « Curvature Contrast in Stereoscopically-Defined Surfaces », Current psychology letters [Online], 2000/1, 1 | 2000, Online since 04 September 2003, connection on 08 September 2020. URL : http://journals.openedition.org/cpl/110 ; DOI : https://doi.org/10.4000/cpl. 110

This text was automatically generated on 8 September 2020

(c) All rights reserved 


\section{Curvature Contrast in Stereoscopically-Defined Surfaces}

S.F. te Pas, B.J. Rogers and T. Ledgeway 